\title{
Electroreductive Olefin-Ketone Coupling
}

\author{
Pengfei $\mathrm{Hu}^{1,3}$, Byron K. Peters ${ }^{1,3}$, Christian A. Malapit',3, Julien C. Vantourout ${ }^{1,3}$, Pan Wang4, \\ Jinjun Li4, Lucas Mele5, Pierre-Georges Echeverria5, Shelley D. Minteer ${ }^{2,3 *}$, and Phil S. Baran ${ }^{1,3^{*}}$. \\ ${ }^{1}$ Department of Chemistry, Scripps Research, 10550 North Torrey Pines Road, La Jolla, CA 92037, United States. \\ 2Department of Chemistry, University of Utah, 315 South 1400 East, Room 2020, Salt Lake City, UT 84112, United States. \\ 3NSF Center for Synthetic Organic Electrochemistry, University of Utah, 315 South 1400 East, Salt Lake City, UT 84112, United \\ States. \\ ${ }^{4}$ Center for Excellence of Process Science, Asymchem Laboratories (Tianjin) Co., Ltd. TEDA, Tianjin 300457, P. R. China. \\ 5Minakem Recherche, 145 Chemin des Lilas, 59310 Beuvry-la-Forêt, France.
}

\section{Ketyl-Olefin, Ketyl, electrochemical Grignard, electrochemical coupling, reductive coupling.}

\begin{abstract}
A user-friendly approach to sidestep the venerable Grignard addition to unactivated ketones to access tertiary alcohols by reversing the polarity of the disconnection. In this work a ketone instead acts as a nucleophile when adding to simple unactivated olefins to accomplish the same overall transformation. The scope of this coupling is broad as enabled using an electrochemical approach and the reaction is scalable, chemoselective, and requires no precaution to exclude air or water. Multiple applications demonstrate the simplifying nature of the reaction on multi-step synthesis and mechanistic studies point to an intuitive mechanism reminiscent of other chemical reductants such as $\mathrm{SmI}_{2}$ (which cannot accomplish the same reaction).
\end{abstract}

Tertiary alcohols are an abundant functional group with versatile reactivity that are found in natural products, ${ }^{1}$ pharmaceuticals, ${ }^{2}$ and a multitude of useful materials. ${ }^{3}$ Traditionally, perhaps overwhelmingly, the ketone has served as a loyal progenitor of this species (Figure 1A) for good reasons. Every undergraduate organic textbook prescribes a direct nucleophilic addition of a strong nucleophile, such as RMgX or RLi, to these electrophilic species. 4 Although these incredibly robust reactions have been employed countless times, they can indirectly contribute to synthetic inefficiencies as their low chemoselectivity often necessitates the use of protecting groups. 5 This dilemma is nicely illustrated (Figure $1 \mathrm{~B}$ ) by examining the patented route to steroid derivative 2. ${ }^{6}$ Although a Grignard reaction with commercially available ketone $\mathbf{1}$ is an obvious disconnection, its use introduces several protecting group additions, removals and functional group manipulations throughout the course of a seven-step sequence (only one of which forges a $\mathrm{C}-\mathrm{C}$ bond).

Within the specific realm of intermolecular alkyl nucleophile additions to unactivated ketones, Grignard and related organometallic additions are fundamentally limited by their 2-electron mechanisms, which render these nucleophiles both strongly nucleophilic and often highly basic.4,5,7 Efforts to tone down their reactivity have been explored, with the most successful stemming from nucleophiles bearing activated positions (i.e. allylic, benzylic, propargylic, $\alpha$-carbonyl, Figure 1C).8,9 Studies employing $\mathrm{Zr}-{ }^{10} \mathrm{Ti}^{-},{ }^{11} \mathrm{Ru}-,{ }^{12}$ and Os-13 based systems, as well as HAT chemistry, ${ }^{14}$ have also pointed to the use of olefins as precursors to species capable of adding to carbonyl groups although intermolecular additions into unactivated ketones are without

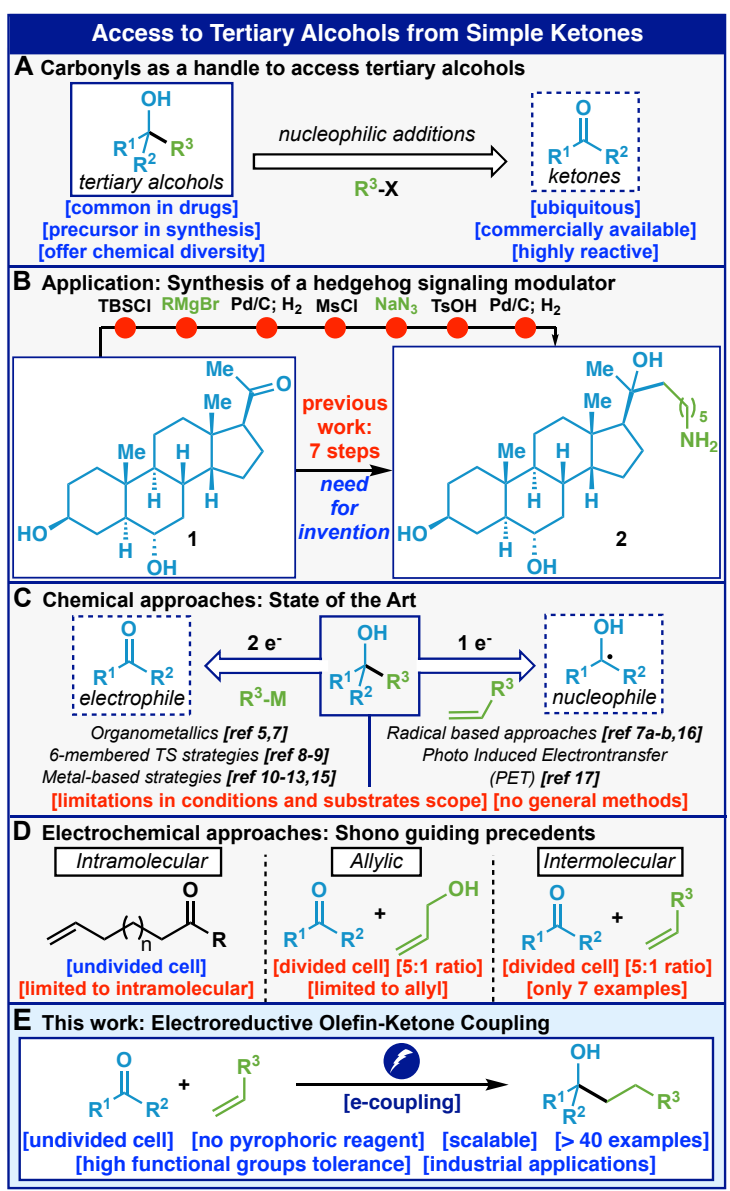

FIGURE 1. Tertiary alcohols from simple ketones remain a challenge for modern synthesis (A). Synthesis of $\mathbf{2}$ is em- 
blematic of the problems with Grignard (B). Recent approaches so far do not address the problem (C). Electrochemical precedent on activated olefins (D) and a sum mary of this work (E).

precedent. ${ }^{15} \mathrm{~A}$ less intuitive approach involves an umpolung disconnection, which renders the ketone the nucleophilic group through a reductive 1-electron approach. Thus far, such approaches have relied primarily on $\mathrm{Sm}(\mathrm{II}),{ }^{\mathrm{a}-\mathrm{b}} \mathrm{Ti}(\mathrm{III}),{ }^{16}$ or photoinduced electron transfer ${ }^{17}$ to couple activated olefins and styrenes to ketones. A general intermolecular reductive coupling of unactivated ketones and olefins is so far absent from the literature. The closest precedent for the desired transformation was disclosed by Shono and co-workers (Figure 1D). ${ }^{18}$ These reports focus predominantly on intramolecular couplings, ${ }^{18 a-b}$ with only a few intermolecular examples ${ }^{18 c-d}$ presented. To the best of our knowledge, this chemistry has not been applied in the literature, despite being available for decades, presumably due to the challenges of using a divided cell setup under an argon atmosphere and the need for at least a five-fold excess of the ketone. In this Communication, a new protocol for electrochemically driven reductive couplings of unactivated ketones and olefins is presented. This method uses a simple undivided cell tolerating exogenous air and moisture, exhibits a broad scope, and can be easily scaled (Figure 1E).

Explorations began by studying Shono's original conditions ${ }^{18 \mathrm{c}}$ on a medicinally-relevant model substrate pair: homoallylic alcohol 4 and piperidone 3 (Table 1A). In principle, the use of Grignard chemistry to carry out this assembly would necessitate the use of a protecting group on 4 and perhaps other precautions due to the enolizability of $\mathbf{3}$, hence, more gentle methodologies were sought. Revisiting the electrochemical method developed by Shono for less ornate substrates, ${ }^{18 c}$ only resulted in low yields (Table $1 \mathrm{~A}$, entry 1 ). This method was pursued with some rigor (see SI for a full listing); however, the yield could not be improved beyond $17 \%$. Chemical reductants such as $\mathrm{SmI}_{2}$ and LiDBB were examined next, and while these methods have been shown to have success in similar intramolecular scenarios, they were found to be unsatisfactory for this purpose (entries 2-5, Table 1a). Developing this chemistry following the guiding principles from our own forays ${ }^{19,20}$ into electrochemistry, specifically deeply reductive electrochemistry, ${ }^{20}$ allowed us to hone in on the sacrificial anode, electrolyte, current density and concentration needed to facilitate a high yielding olefin-ketone coupling (Table 1A, see the SI for a full listing). As graphically illustrated in Table $1 \mathrm{~B}$, these three variables were crucial to the success of this transformation which, after optimization, let to 95\% isolated yield of adduct $\mathbf{5}$ (Table 1A, entry 6). The use of an inexpensive sacrificial anode ( $\mathrm{Zn})$ was ideal and, in contrast to prior work, a lower current ensured broad functional group tolerance (10 mA vs. $200 \mathrm{~mA}$ ). Notably, unlike prior precedent, only 2 equivalents of the ketone are required, inexpensive electrodes are employed, and an operationally simple undivided cell is used. No precautions are taken to exclude air or moisture and in fact the reaction can be run open to the air (cap removed). Finally, the linear versus branched selectivity is remarkable ( $>15: 1$ in most of the cases).
TABLE 1. Optimization of the reductive ketone olefin coupling. Comparison to known chemical methods (A) and a graphical optimization overview of the newly developed electrochemical protocol (B).

Optimization of the Electroreductive Olefin-Ketone Coupling

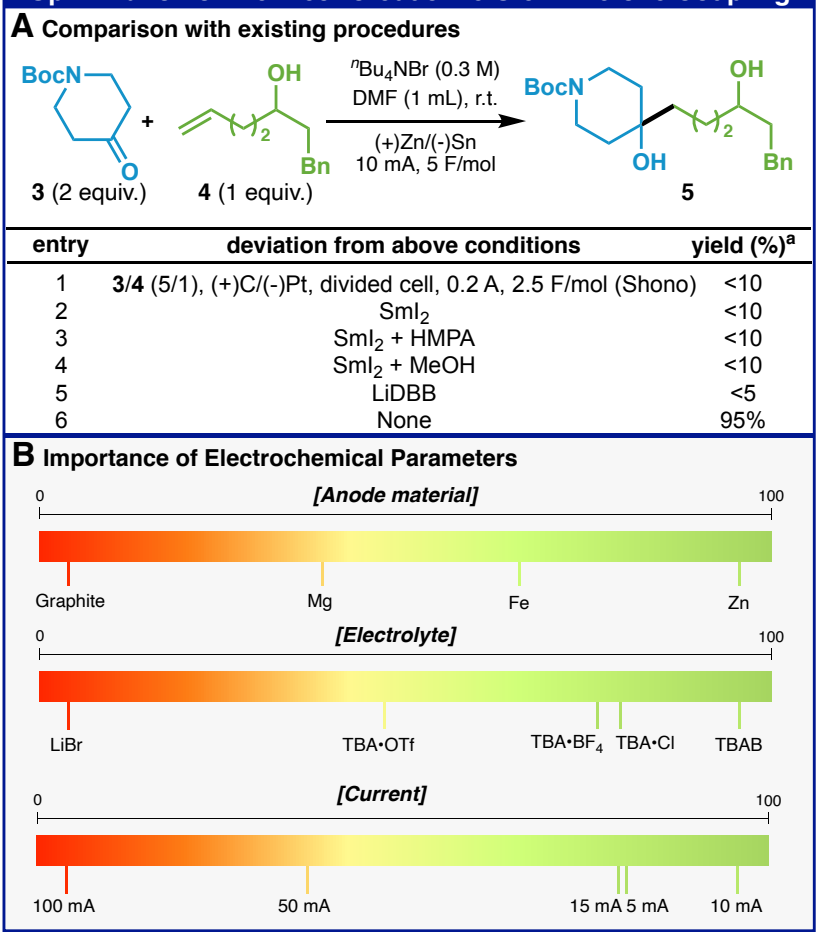

With these results in hand, the scope of the ketone-olefin coupling was investigated (Table 2). Several functionalities on the olefin were tolerated; free alcohols $\left(1^{\circ}, 2^{\circ}\right.$, and $3^{\circ} ; \mathbf{6}$ to 8), aniline (9), amides $(\mathbf{1 0}, \mathbf{1 3}, \mathbf{2 1})$, nitrile (11), ester (12), protected amino acid (14), and heterocycles (15-19) (moderate to high yields). Most of these functional groups would be challenging to employ using canonical $2 \mathrm{e}^{-}$tactics such as Grignard. The reaction tolerated mono-substituted olefins well, but performed less successfully with 1,1-di (22) and 1,2-di (23) substituted olefins - tri- and tetra-substituted olefins were not tolerated, and no reaction was observed in these cases. A plausible reason for this lack of reactivity with more substituted olefins could be due to a slower rate of addition (for steric reasons) compared to the lifetime of the ketyl radical. In the case of cyclopentene-3-ol, an interesting finding was that the reaction took place in high yield with perfect syn diastereoselectivity. The analogous TBSprotected olefin did not react, nor did cyclopentene itself. The directing effect of homo-allylic alcohols in this chemistry is notable and perhaps relevant to the mechanism of the reaction (vide infra).

In a similar fashion, ketones bearing several different substituents were tolerated (moderate to high yields); ethers (26), protected amines (36-37), esters (39), carbamates (43), alcohols (50-51), cyclopropanes (52). When 4-substituted cyclohexanones were used, single diastereomers were isolated with the selectivity reminiscent of $\mathrm{SmI}_{2}$ promoted reactions (anti, 38-39). ${ }^{21}$ Even cyclic ketones of varying ring sizes (24-39) worked well, which are often challenging for other methods; reduction products 
TABLE 2. Scope of the electroreductive olefin-ketone coupling.

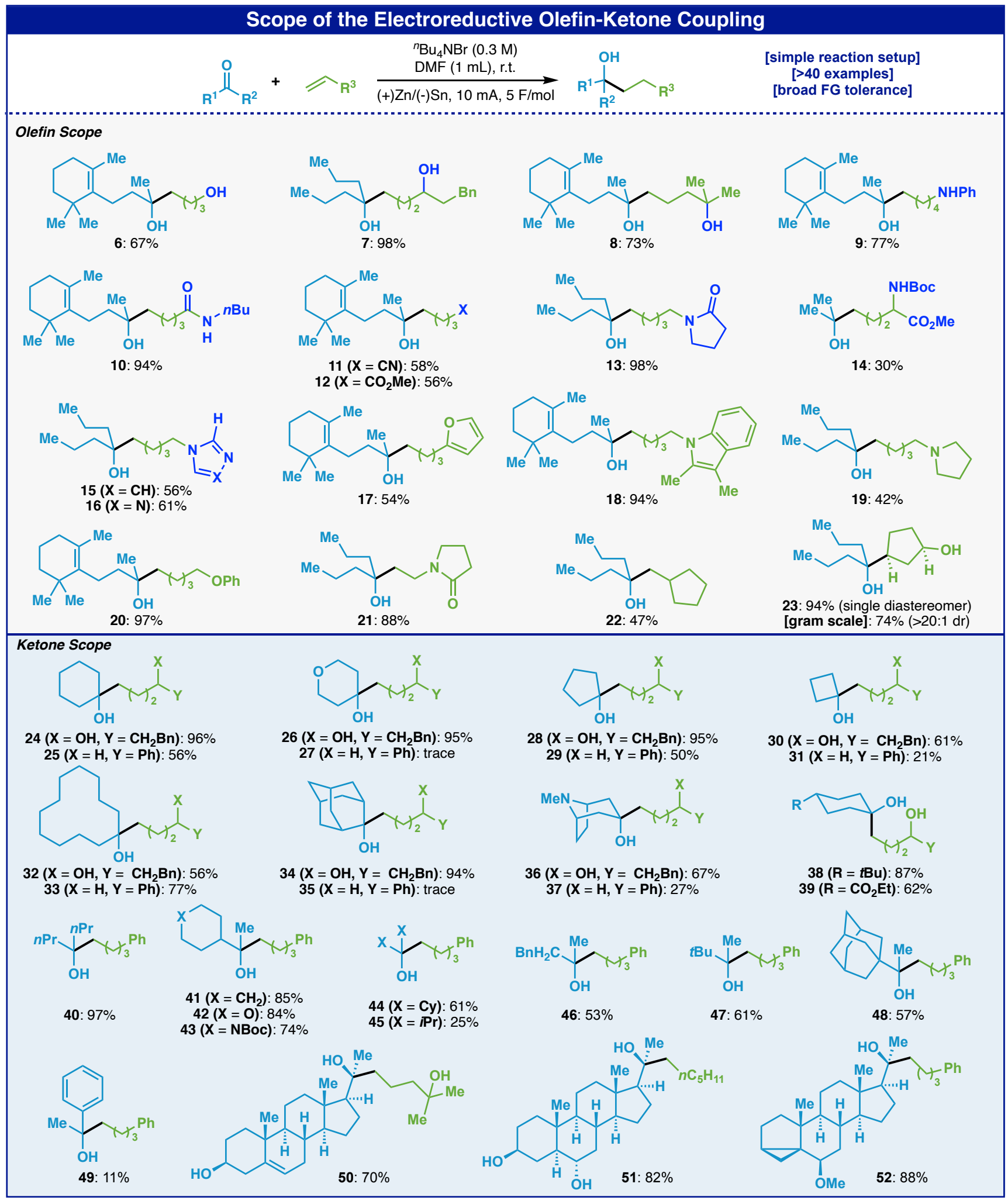

are often observed when sterically hindered ketones react with Grignards. For acyclic ketones, the sterics of the substituents showed a minor impact on the reaction yields (40-48), although only $25 \%$ yield of the desired product was isolated when very hindered diisopropylketone (45) was used. Notably, unprotected steroidal substrates 50-52 delivered a single diastereomeric product in high yield (see SI for structure confirmation). 


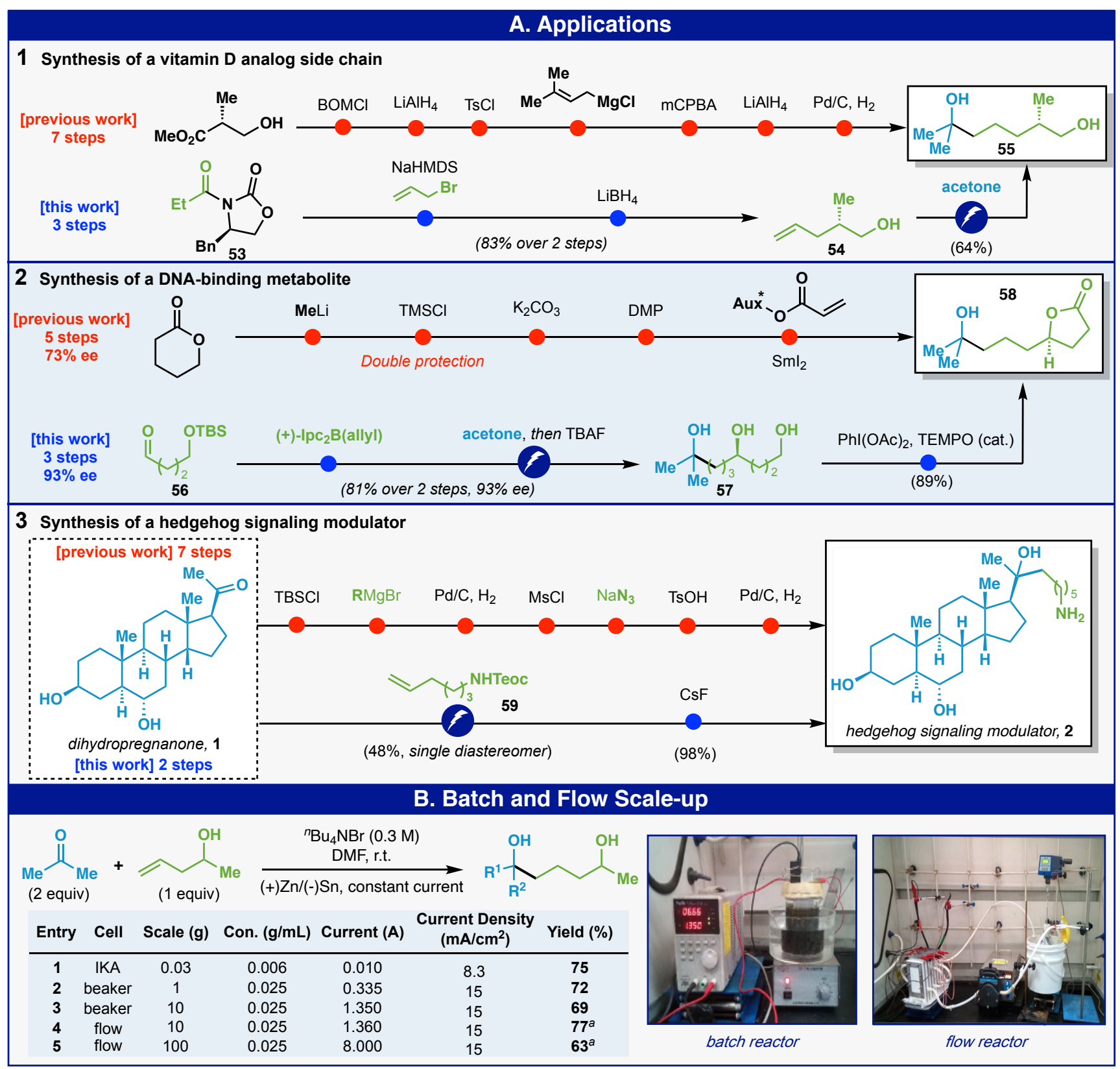

SCHEME 1. (A) Electrochemical ketone-olefin coupling facilitates rapid access to medicinally relevant structures such as a vitamin D sidechain (1), a DNA-binding metabolite (2), and a hedgehog signaling modulator (3). (B) Batch and flow scale-up. ${ }^{a}$ Isolated yield

This reductive coupling could also be applied to simplify real-world challenges in medicinal chemistry (Scheme 1). Thus, the synthesis of a simple vitamin $\mathrm{D}$ analog sidechain 55 was reported through a seven-step route wherein only one of those steps formed a $\mathrm{C}-\mathrm{C}$ bond (Scheme $1 \mathrm{~A}) .{ }^{22}$ In contrast, commercially available oxazolidinone 53 could be allylated and reduced to yield $(S)$-2 methyl-4-penten1-ol 54. Coupling of $\mathbf{5 4}$ with acetone under the developed electrochemical conditions then smoothly furnished sidechain 55. Of the three steps required to access 55, two forged key $\mathrm{C}-\mathrm{C}$ bonds. Next, the synthesis of DNAbinding metabolite $\mathbf{5 8}$ required a five-step sequence with two protecting groups and air-sensitive $\mathrm{SmI}_{2}$ to forge a key $\mathrm{C}-\mathrm{C}$ bond (73\% ee, Scheme $1 \mathrm{~B}) .{ }^{23}$ Using the electrochemical strategy outlined above, commercially available aldehyde $\mathbf{5 6}$ could be converted to the same product in only 3 steps via simple Brown allylation, followed by electrochemical addition of acetone/TBAF work-up and a final oxidative lactonization ( $72 \%$ yield, 93\% ee). Finally, the steroidal example ${ }^{6}$ mentioned in Figure 1 could be addressed in a similar way from the same starting material (Scheme $1 \mathrm{C}$ ). Thus, electrochemical addition of $\mathbf{1}$ to Teocprotected amine 59 delivered a single diastereomeric tertiary alcohol that, after $\mathrm{CsF}$-induced deprotection delivered 2 in only 2 steps. Clearly, the success of the above applications benefits from the chemoselective (FG tolerant) nature of the electrochemical ketone-olefin coupling. 


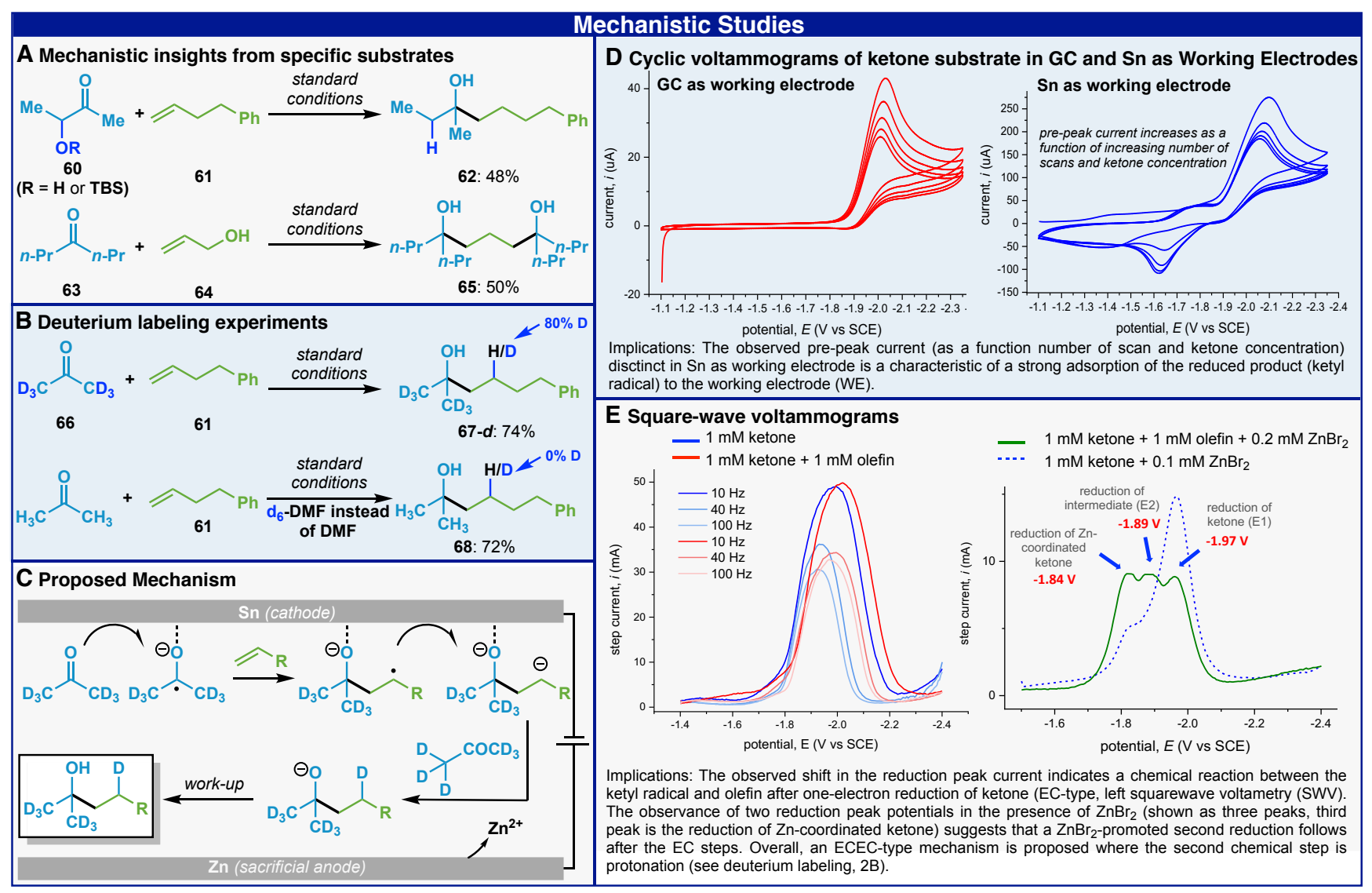

SCHEME 2. Mechanistic insights from byproducts (A), deuterium labeling (B), proposed reaction mechanism (C), and voltammetry studies (D \& E). See SI for details.

In terms of limitations, currently, ketones bearing an $\alpha$ heteroatom are not tolerated (as they are reduced, vide infra) and heterocycles with a higher reductive potential than the ketone are not tolerated, such as thiophenes and simple pyridines (see SI for a full list of failed substrates).

The mechanism of this useful reaction (Scheme 2) was next interrogated through the observation of certain sideproducts (Scheme 2A), deuterium labeling (Scheme 2B), kinetics, and voltammetric studies (Scheme 2D \& 2E). A notable limitation of this chemistry was that ketones bearing alpha-substituents (such as 6o) were not tolerated and elimination of the alpha-substituent was observed (62), suggestive of a ketyl radical intermediate. Using allyl alcohol (64), the bis addition adduct 65 was observed, perhaps pointing to a carbanion intermediate wherein $\mathrm{ZnBr}_{2}$ generated from anodic oxidation could assist in the departure of the primary alcohol and regeneration of another olefin. Deuterium labeling using acetone- $\mathrm{d}_{6}$ led to $70 \%$ incorporation at the highlighted position (Scheme 2B) further supporting a carbanion intermediate. When regular acetone was used in the same experiment but with deuterated DMF, no deuterated product was observed. Kinetic studies revealed zero-order dependence on all components except current indicating that reduction is purely electrochemical.

Finally, a series of voltammetric studies were performed (Scheme 2D \& 2E) to understand how traditionally nucle ophilic ketyl radical can serve as competent coupling partners with unactivated olefins, as well as to provide evidence for the overall electrochemical mechanistic sequence as proposed in Scheme $2 \mathrm{C}$. We hypothesized that the change in its electronic property and reactivity can be facilitated by a strong adsorption of the ketyl radical to the Sn electrode. Cyclic voltammetry studies were performed using Sn and glassy carbon (GC) as working electrodes with acetophenone ${ }^{24}$ as the source of ketyl radical. Prepeaks on the CV were observed using Sn as the working electrode but not observed using GC as the working electrode. These pre-peaks are distinct characteristics of an electron transfer where the product (ketyl radical) is strongly adsorbed into the working electrode. ${ }^{25}$ Furthermore, the current response observed in the pre-peak in $\mathrm{Sn}$ was found to be dependent on the concentration of ketone (see SI). ${ }^{26}$ This result also rationalizes the effectiveness of using Sn-cathode over other electrode materials (see SI). Square-wave voltammetry (SWV) studies were performed and the results are summarized in Scheme 2E. The addition of alkene $\mathbf{6 1}$ to acetophenone showed an anodic shift in the cathodic peak potential denoting a chemical reaction with the ketyl radical after one-electron reduction. However, even at high frequencies $(100 \mathrm{~Hz})$, the expected second reduction peak was not observed. We hypothesized that one crucial role of the sacrificial $\mathrm{Zn}$-anode is to provide $\mathrm{Zn}^{2+}$ as a thermodynamic sink for the second electron reduction. SWV analysis in the presence of catalytic amounts of $\mathrm{ZnBr}_{2}$ showed three distinct reduction peaks where the third peak can be the reduction of the $\mathrm{ZnBr}_{2}$ - 
coordinated ketone (see SI). Taken together, these results suggest an ECEC-type electrochemical mechanism where the ketyl radical formation (E) takes place at the Sn-cathode with strong adsorption characteristic followed by radical addition (C) into the olefin. A second one-electron reduction (second $\mathrm{E}$ ) of the radical anion to the dianion followed by protonation (second C) and then workup delivers the final product. The enhanced reactivity of homoallylic alcohols may be due to improved binding of the olefin substrate to the cathode surface.

In summary, a chemoselective, scalable method to combine unactivated olefins and ketones has been developed that subverts the issues encountered using Grignard reagents in conventional retrosynthetic analysis. The scope of this reaction is broad and it is operationally simple to perform. A number of applications demonstrate that the utility extends beyond that of a simple tactical change as when strategically employed, it can dramatically reduce overall step count. Mechanistic studies point to an intuitive electrochemically driven reductive pathway that initiates upon the formation of a ketyl radical, addition to the olefin, and further reduction to a stabilized carbanion prior to workup. This work is thus another example of how strongly reducing chemistry can be uniquely facilitated and enabled in complex settings under electrochemical control when classical chemical reagents fail.

\section{AUTHOR INFORMATION}

\section{Corresponding Authors}

*pbaran@scripps.edu

*minteer@chem.utah.edu

\section{Author Contributions}

The manuscript was written through contributions of all authors. All authors have given approval to the final version of the manuscript.

\section{ACKNOWLEDGMENT}

Financial support for this work was provided by NIH (GM118176), NSF (CCI Phase 1 grant 1740656 and Phase II grant 2002158), George E. Hewitt Foundation (P.H), and Swedish Research Council (B.K.P). Authors are grateful to Dr. DeeHua Huang and Dr. Laura Pasternack (Scripps Research) for assistance with nuclear magnetic resonance (NMR) spectroscopy, to Dr. Jason Chen, Brittany Sanchez and Emily Sturgell (Scripps Automated Synthesis Facility) for assistance with HPLC, HRMS and LCMS, to Dr. James R. Gage, Dr. Yi Hsiao and Dr. Enxuan zhang (Asymchem Inc.) for assistance with scale-up reaction.

\section{REFERENCES}

(1) For selected reviews, see: a) Nicolaou, K. C.; Montagnon, T. Molecules That Changed the World. Wiley-VCH (2008); b) Arimoto, H.; Uemura, D. In: Quaternary Stereocenters, Challenges and Solutions for Organic Synthesis; (Eds.: J. Christoffers, A. Baro), Wiley-VCH, Weinheim, 2005, chap.1, pp 1-24; c) de Vries, J. G. in: Quaternary Stereocenters, Challenges and Solutions for Organic Synthesis; (Eds.: J. Christoffers, A. Baro), Wiley-V CH, Weinheim, 2005, chap. 2, pp 25-50.

(2) For selected reviews, see: a) Motwani, H. V.; De Rosa, M.; Odell, L. R.; Hallberg, A.; Larhed, M. Aspartic protease inhibitors containing tertiary alcohol transition-state mimics. Eur. $J$. Med. Chem. 2015, 9o, 462-490; b) Talele, T. T.; Natural-Products-Inspired Use of the gem-Dimethyl Group in Medicinal
Chemistry. J. Med. Chem. 2018, 61, 2166-2210; c) Cramer, J.; Sager, C. P.; Ernst, B. Hydroxyl Groups in Synthetic and NaturalProduct-Derived Therapeutics: A Perspective on a Common Functional Group. J. Med. Chem. 2019, 62, 8915-8930.

(3) For selected reviews, see: (a) Chen, L.; Yin, X.-P.; Wang, C.-H.; Zhou, J. Catalytic functionalization of tertiary alcohols to fully substituted carbon centres. Org. Biomol. Chem. 2014, 12, 6033-6048.; (b) Naredla, R. R.; Klumpp, D. A. Contemporary Carbocation Chemistry: Applications in Organic Synthesis. Chem. Rev. 2013, 113, 6905-6948.

(4) For a selected example, see: Vollhardt, K.; Schore, N. Organic Chemistry: Structure and Function; W. H. Freeman: New York, 2014.

(5) For selected reviews, see: (a) Rappoport, Z., Marek, I., Eds. The Chemistry of Organomagnesium Compounds; Wiley-VCH: Weinheim, Germany, 2008; (b) Seyferth, D. The Grignard Reagents. Organometallics 2009, 28, 1598-1605; (c) Silverman, G. S.; Rakita, P. E. Handbook of Grignard Reagents; CRC Press: New York, 1996; (d) Knochel, P.; Dohle, W.; Gommermann, N.; Kneisel, F. F.; Kopp, F.; Korn, T.; Sapountzis, I.; Vu, V. A. Highly Functionalized Organomagnesium Reagents Prepared through Halogen-Metal Exchange. Angew. Chem., Int. Ed. 2003, 42, 4302-4320; (e) Rappoport, Z.; Marek, I., Eds. The Chemistry of Organolithium Compounds, Wiley-VCH, 2004; (f) Luisi, R.; Capriati, V. Eds. Lithium Compounds in Organic Synthesis From Fundamentals to Applications, Wiley-VCH, 2014.

(6) Xiao, W.; Epperson, M.; Farouz, F.; Stappenbeck, F.; Thorsett, E. Oxysterol compounds. WO2012/024584A2.

(7) For reviews of nucleophiles other than R-MgX or R-Li, see: (a) Szostak, M.; Fazakerley, N. J.; Parmar, D.; Procter, D. J. Cross-Coupling Reactions Using Samarium(II) Iodide. Chem. Rev. 2014, 114, 5959-6039; (b) Nicolaou, K. C.; Ellery, S. P.; Chen, J. S. Samarium Diiodide Mediated Reactions in Total Synthesis. Angew. Chem. Int. Ed. 2009, 48, 7140-7165; (c) Reetz, M. T.; Westermann, J.; Steinbach, R.; Wenderoth, B.; Peter, R.; Ostarek, R.; Maus, S. Chemoselective Addition of Organotitaniurn Reagents to Carbonyl Compounds. Chem. Ber. 1985, 118, 1421-1440; (d) Knochel, P.; Jones, P. Organozinc Reagents; Oxford University Press: Oxford, 1999; (e) Weidmann, B.; Seebach, D. Organometallic Compounds of Titanium and Zirconium as Selective Nucleophilic Reagents in Organic Synthesis. Angew. Chem. Int. Ed. 1983, 22, 31-45; (f) Marek, I. Titanium and Zirconium in Organic Synthesis. Wiley-VCH, 2002; (g) Liu, H.-S.; Shia, K.-S.; Shang, X.; Zhu, B.-Y.; Shang, X.; Zhu, B.-Y. Organocerium Compounds in Synthesis. Tetrahedron 1999, 55, 3803-3830.

(8) For selected reviews, see: (a) Holmes, A.; Schwartz, L. A.; Krische, M. J. Intermolecular Metal-Catalyzed Reductive Coupling of Dienes, Allenes, and Enynes with Carbonyl Compounds and Imines. Chem. Rev. 2018, 118, 6026-6052; (b) Yus, M.; Gonzalez-Go 'mez, J. C.; Foubelo, F. Catalytic Enantioselective Allylation of Carbonyl Compounds and Imines. Chem. Rev. 2011, 111, 7774-7854; (c) Shibashaki, M.; Kanai, M. Asymmetric Synthesis of Tertiary Alcohols and -Tertiary Amines via Cu-Catalyzed C-C Bond Formation to Ketones and Ketimines. Chem. Rev. 2008, 108, 2853-2873; (d) Denmark, S. E.; Fu, J. Catalytic Enantioselective Addition of Allylic Organometallic Reagents to Aldehydes and Ketones. Chem. Rev. 2003, 103, 2763-2793; (e) $\mathrm{Pu}, \mathrm{L} . ; \mathrm{Yu}, \mathrm{H} .-\mathrm{B}$. Catalytic Asymmetric Organozinc Additions to Carbonyl Compounds. Chem. Rev. 2001, 101, 757-824; (f) Diner, C.; Szabó, K. J. Recent Advances in the Preparation and Application of Allylboron Species in Organic Synthesis. J. Am. Chem. Soc. 2017, 139, 2-14; (g) Leonori, D.; Aggarwal, V. K. Lithiation-Borylation Methodology and Its Application in Synthesis. Acc. Chem. Res. 2014, 47, 3174-3183; (h) Riant, O.; Hannedouche, J. Asymmetric catalysis for the construction of quaternary carbon centres: nucleophilic addition on ketones and ketimines. Org. Biomol. Chem. 2007, 5, 873-888; (i) Liu, Y.-L.; Lin, X.-T. Recent Advances in Catalytic Asymmetric Synthesis of Tertiary Alcohols via Nucleophilic Addition to Ketones. $A d v$. Syn. Catal. 2019, 361, 876-918. 
(9) For recent examples, see: (a) Miller, J. J.; Sigman, M. S. Design and Synthesis of Modular Oxazoline Ligands for the Enantioselective Chromium-Catalyzed Addition of Allyl Bromide to Ketones. J. Am. Chem. Soc. 2oo7, 129, 2752-2753; (b) Barnett, D. S.; Moquist, P. N.; Schaus, S. E. Angew.Chem. Int. Ed. 2009, 48, 8679-8682; (c) Shi, S.-L.; Xu, L.-W.; Oisaki, K.; Kanai, M.; Shibasaki, M. J. Am. Chem. Soc. 2010, 132, 6638-6639; (c) Saxena, A.; Choi, B.; Lam, H. W. Enantioselective Copper Catalyzed Reductive Coupling of Alkenylazaarenes with Ketones. $J$. Am. Chem. Soc. 2012, 134, 8428-8431; (d) Meng, F.; Jang, H.; Jung, B.; Hoveyda, A. H. Cu-Catalyzed Chemoselective Preparation of 2-(Pinacolato)boron-Substituted Allylcopper Complexes and their In Situ Site-, Diastereo-, and Enantioselective Additions to Aldehydes and Ketones. Angew. Chem. Int. Ed. $\mathbf{2 0 1 3}$ 52, 5046-5051; (e) Zhang, Y.; Li, N.; Qu, B.; Ma, S.; Lee, H.; Gonnella, N. C.; Gao, J.; Li, W.; Tan, Z.; Reeves, J. T.; Wang, J.; Lorenz, J.C.; Li, G.; Reeves, D. C.; Premasiri, A.; Grinberg, N.; Haddad, N.; Lu, B. Z.; Song, J. J.; Senanayake, C. H. Org. Lett. 2013, 15, 1710-1713. (f) Yang, Y.; Perry, I. B.; Lu, G.; Liu, P.; Buchwald, S. L. Copper-Catalyzed Asymmetric Addition of Olefin Derived Nucleophiles To Ketones. Science 2016, 353, 144-150; (g) Robbins, D. W.; Lee, K. A.; Silverio, D. L.; Volkov, A.; Torker, S.; Hoveyda, A. H. Practical and Broadly Applicable Catalytic Enantioselective Additions of Allyl - B(pin) Compounds to Ketones and $\alpha$-Ketoesters. Angew. Chem. Int. Ed. 2016, 55, 9610-9614; (h) Tsai, E. Y.; Liu, R. Y.; Yang, Y.; Buchwald, S. L. A Regio- and Enantioselective CuH-Catalyzed Ketone Allylation with Terminal Allenes. J. Am. Chem. Soc. 2018, 14O, 2007-2011. (i) Li, K.; Shao, X.; Tseng, L.; Malcolmson, S. J. 2Azadienes as Reagents for Preparing Chiral Amines: Synthesis of 1,2-Amino Tertiary Alcohols by Cu-Catalyzed Enantioselective Reductive Couplings with Ketones. J. Am. Chem. Soc. 2018, 14O, 598-601; (j) Li, C.; Liu, R. Y.; Jesikiewicz, L. T.; Yang, Y.; Liu, P.; Buchwald, S. L. J. Am. Chem. Soc. 2019, 141, 5062-5070; (k) Brito, G. A.; Jung, W.-O’ Yoo, M.; Krische, M. J. Enantioselective Iridium-Catalyzed Allylation of Acetylenic Ketonesvia 2-Propanol-Mediated ReductiveCoupling of Allyl Acetate: C14-C23 of Pladienolide D. Angew. Chem. Int. Ed. 2019, 58, 18803-18807; (l) Schewarz, J. L.; Kleinmans, R.; Paulisch, T. O.; Glorius, F. 1,2Amino Alcohols via $\mathrm{Cr} /$ Photoredox Dual-Catalyzed Addition of a-Amino Carbanion Equivalents to Carbonyls. J. Am. Chem. Soc. 2020, 142, 2168-2174.

(10) (a) Negishi, E.; Takahashi, T. Organozirconium Compounds in Organic Synthesis. Synthesis 1988, 1-19; (b) Hirao, Y.; Katayama, Y.; Mitsunuma, H.; Kanai, M. Chromium-Catalyzed Linear-Selective Alkylation of Aldehydes with Alkenes. Org. Lett. 2020 asap, doi: 10.1021/acs.orglett.oco3180.

(11) (a) Kablaoui, N. M.; Buchwald, S. L. Reductive Cyclization of Enones by a Titanium Catalyst. J. Am. Chem. Soc. 1995, 117 6785-6786; (b) Kablaoui, N. M.; Buchwald, S. L. Development of a Method for the Reductive Cyclization of Enones by a Titanium Catalyst. J. Am. Chem. Soc. 1996, 118, 3182-3291; c) Crowe, W. E.; Rachita, M. J. Titanium-Catalyzed Reductive Cyclization of $\delta, \varepsilon$-Unsaturated Ketones and Aldehydes. J. Am. Chem. Soc. 1995, 117, 6787-6788.

(12) Yamaguchi, E.; Mowat, J.; Luong, T.; Krische, M. J. Regio- and Diastereoselective $\mathrm{C}-\mathrm{C}$ coupling of $\alpha$-Olefins and Styrenes to 3-Hydroxy-2-oxindoles by Ru-Catalyzed Hydrohydroxyalkylation. Angew. Chem. Int. Ed. Engl. 2013, 52, 8428-8431.

(13) Park, B. Y.; Luong, T.; Sato, H.; Krische, M. J. Osmium(o) Catalyzed $\mathrm{C}-\mathrm{C}$ Coupling of Ethylene and $\alpha$-olefins with Diols, Ketols or Hydroxy Esters via Transfer Hydrogenation. J. Org. Chem. 2016, 81, 8585-8594.

(14) Saladrigas, M.; Bosch, C.; Saborit, G. V.; Bonjoch, J.; Bradshaw, B. Radical Cyclization of Alkene-Tethered Ketones Initiated by Hydrogen-Atom Transfer. Angew. Chem. Int. Ed. 2018, 57, 182-186.

(15) Nguyen, K. D.; Park, B. Y.; Luong, T.; Sato, H.; Garza, V. J.; Krische, M. J. Metal-Catalyzed Reductive Coupling of OlefinDerived Nucleophiles: Reinventing Carbonyl Addition. Science 2016, 354, aah5133.
(16) For selected reviews, see: a) McCallum, T.; Wu, X.; Lin, S. Recent Advances in Titanium Radical Redox Catalysis. J. Org. Chem. 2019, 84, 14369-14380; b) Castro Rodríguez, M.; Rodríguez Garcia, I.; Rodríguez Maecker, R. N.; Pozo Morales, L.; Oltra, J. E.; Rosales Martínez, A. $\mathrm{Cp}_{2} \mathrm{TiCl}$ : An Ideal Reagent for Green Chemistry? Org. Process Res. Dev. 2017, 21, 911-923.; c) Morcillo, S. P.; Miguel, D.; Campaña, A. G.; Álvarez de Cienfuegos, L.; Justicia, J.; Cuerva, J. M. Recent applications of $\mathrm{Cp}_{2} \mathrm{TiCl}$ in natural product synthesis. Org. Chem. Front. 2014, $1,15-33$.

(17) Seo, H.; Jamison, T. F. Catalytic Generation and Use of Ketyl Radical from Unactivated Aliphatic Carbonyl Compounds. Org. Lett. 2019, 21, 10159-10163.

(18) (a) Shono, T.; Mitani, M. Electroorganic Chemistry. VIII. Intramolecular Cycloaddition of Nonconjugated Olefinic Ketones to Form Cyclic Tertiary Alcohols. J. Am. Chem. Soc. 1971, 93, 5284-5286; (b) Shono, T.; Nishiguchi, I.; Ohmizu, H.; Mitani, M. Electroorganic Chemistry. 31. Reductive Cyclization of Nonconjugated Olefinic Ketones to Cyclic Tertiary Alcohols. $J$. Am. Chem. Soc. 1978, 10o, 545-550; (c) Shono, T.; Kashimura, S.; Mori, Y.; Hayashi, T.; Soejima, T.; Yamaguchi, Y. Electroreductive Intermolecular Coupling of Ketones with Olefins. J. Org. Chem. 1989, 54, 6001-6003; (d) Shono, T.; Morishima, Y.; Moriyoshi, N.; Ishifune, M. Electroreductively Promoted Diastereoselective Coupling of Ketones with Allylic Alcohols. Synthesis of Optically Active 1,4-Diols. J. Org. Chem. 1994, 59, 273-275.

(19) For reviews, see: (a) Horn, E. J.; Rosen, B. R.; Baran, P. S. Synthetic Organic Electrochemistry: An Enabling and Innately Sustainable Method. ACS Cent. Sci. 2016, 2, 302-308; (b) Yan, M.; Kawamata, Y.; Baran, P. S. Synthetic Organic Electrochemical Methods Since 2000: On the Verge of a Renaissance. Chem. Rev. 2017, 117, 13230-13319; (c) Kingston, C.; Palkowitz, M. D.; Takahira, Y.; Vantourout, J. C.; Peters, B. K.; Kawamata, Y.; Baran, P. S. A Survival Guide for the "Electro-curious". Acc. Chem. Res. 2020, 53, 72-83.

(20) Peters, B. K.; Rodriguez, K. X.; Reisberg, S. H.; Beil, S. B.; Hickey, D. P.; Kawamata, Y.; Collins, M.; Starr, J.; Chen, L.; Udyavara, S.; Klunder, K.; Gorey, T. J.; Ander, S. L.; Neurock, M.; Minteer, S. D.; Baran, P. S. Scalable and Safe Synthetic Organic Electroreduction Inspired by Li-ion Battery Chemistry. Science 2019, 363, 838-845.

(21) (a) Fukuzawa, S.; Nakanishi, A.; Fujinami, T.; Sakai, S. Samarium(II) Di-iodide Induced Reductive Coupling of $\alpha, \beta$-Unsaturated Esters with Carbonyl Compounds Leading to a Facile Synthesis of $\gamma$-Lactone. J. Chem. Soc. Perkin Trans I. 1988, 1669-1675; (b) Sono, M.; Shoji, T.; Tamaki, T.; Kishi, S.; Tori, M. The Stereochemistry of Electrolysis and Samarium Diiodide-Induced Cyclization Between Carbonyl and Enone System in Interand Intramolecular Coupling. Heterocycles. 2oo7, 72, 517-528.

(22) (a) Plonska-Ocypa, K.; Grzywacz, P.; Sicinski, R. R.; Plum, L. A.; DeLuca, H. F. Synthesis and biological evaluation of

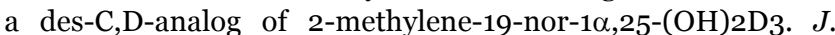
Steroid Biochem. Mol. Biol. 2007, 103, 298-304; (b) PlonskaOcypa, K.; Sicinski, R. R.; Plum, L. A.; Grzywacz, P.; Frelek, J.; Clagett-Dame, M.; DeLuca, H. F. 13-Methyl-substituted des-C,D Analogs of (20S)-1a,25-Dihydroxy-2-methylene-19-norvitamin D3(2MD): Synthesis and Biological Evaluation. Bioorg. Med. Chem. 2009, 17, 1747-1763.

(23) For isolation, see: (a) Maul, C.; Sattler, I.; Zerlin, M.; Hinze, C.; Koch, C.; Maier, A.; Grabley, S.; Thiericke, R. Biomolecular-chemical Screening: A Novel Screening Approach for the Discovery of Biologically Active Secondary Metabolites. III. New DNA-binding Metabolites. J. Antibiot. 1999, 52, 1124-1134; For previous syntheses, see: (b) Kerrigan, N. J.; Hutchison, P. C.; Heightman, T. D.; Procter, D. J. Application of an Ephedrine Chiral Linker in a Solid-phase, 'Asymmetric Catchrelease' Approach to $\gamma$-Butyrolactones. Chem. Commun. 2oo3, 1402-1403; (c) Kerrigan, N. J.; Hutchison, P. C.; Heightman, T. D.; Procter, D. J. Development of a Solid-phase, 'Asymmetric Resin-capture-release' Process: Application of an Ephedrine 
Chiral Resin in an Approach to $\gamma$-Butyrolactones. Org. Biomol. Chem. 2004, 2, 2476-2482.

(24) Acetophenone was used despite low yield was obtained because various dialkyl ketones failed to give a clear reduction peak under CV studies. For a list of dialkyl ketones attempted, see SI Fig. S9. For low electrochemical activity of dialkyl ketone on CV scale, see: Bondue, C. J.; Koper, M. T. M. Electrochemical reduction of the carbonyl functional group: The importance of adsorption geometry, molecular structure, and electrode surface structure. J. Am. Chem. Soc. 2019, 141, 12071-12078.

(25) Wopschall, R. H.; Shain, I. Effects of adsorption of electroactive species in stationary electrode polarography. Anal. Chem. 1967, 39, 1514-1527.

(26) The observed adsorption phenomena of the ketyl radical unto Sn electrode was also supported by CV analysis using various scan rates and chronoamperometric studies (for results and discussion, see SI Figs S7 \& S8). 